University of Nebraska - Lincoln

DigitalCommons@University of Nebraska - Lincoln

US Army Research

U.S. Department of Defense

2005

Brown Recluse Spider Bite to the Face

Daniel C. Madion

Melanie K. Marshall

Christopher D. Jenkins

George M. Kushner

Follow this and additional works at: https://digitalcommons.unl.edu/usarmyresearch

Part of the Operations Research, Systems Engineering and Industrial Engineering Commons

Madion, Daniel C.; Marshall, Melanie K.; Jenkins, Christopher D.; and Kushner, George M., "Brown Recluse Spider Bite to the Face" (2005). US Army Research. 41.

https://digitalcommons.unl.edu/usarmyresearch/41

This Article is brought to you for free and open access by the U.S. Department of Defense at DigitalCommons@University of Nebraska - Lincoln. It has been accepted for inclusion in US Army Research by an authorized administrator of DigitalCommons@University of Nebraska - Lincoln. 


\title{
Brown Recluse Spider Bite to the Face
}

\author{
Daniel C. Madion, DDS, MD, * Melanie K. Marshall, DDS, MD, $†$ \\ Christopher D. Jenkins, DDS, MD, $\neq$ \\ and George M. Kushner, DMD, MD』
}

Oral and maxillofacial surgeons must be prepared to manage a variety of maxillofacial infections, both odontogenic and non-odontogenic in nature. While odontogenic infections are quite common, non-odontogenic infections can present with diagnostic and therapeutic challenges. An uncommon non-odontogenic infection is the cellulitis secondary to a spider bite.

Few spider species have the ability to bite through human skin. Most of these insults result in only a small, red nodule centered within a larger, erythematous plaque. Symptoms are usually limited to pruritus and perhaps mild tenderness. The brown recluse and the black widow are 2 types of spiders that inhabit the United States that can cause serious injury or major medical problems to their victim. ${ }^{1}$ The bite of the brown recluse spider (Loxosceles reclusa) results in an envenomation that can have deleterious effects on the patient.

Within 6 hours after the bite, pain and erythema develop at the site. The area of erythema spreads during the first 24 hours and may turn bluish-purple. Necrosis of the skin often occurs 24 to 48 hours later. Signs include bullae formation, cyanosis, and hyperesthesia. Depending on their size, complete resolution of these lesions can take from weeks to months. Systemic symptoms include fever, chills, malaise, vomiting, and arthralgias. Less common but more severe reactions

\footnotetext{
*Resident, Department of Oral and Maxillofacial Surgery, School of Dentistry, University of Louisville, Louisville, KY.

†Formerly, Chief Resident, Department of Oral and Maxillofacial Surgery, School of Dentistry, University of Louisville, Louisville, KY; Currently, Private Practice, Charlotte, NC.

¥Major, Dental Corps, US Army; Chief, Oral and Maxillofacial Surgery, Ireland Army Community Hospital, Fort Knox, KY.

CAssociate Professor and Residency Program Director, Department of Oral and Maxillofacial Surgery, School of Dentistry, University of Louisville, Louisville, KY.

Address correspondence and reprint requests to Dr Madion: School of Dentistry, University of Louisville, Louisville, KY 40292; e-mail: dcmadi01@1ouisville.edu (c) 2005 American Association of Oral and Maxillofacial Surgeons 0278-2391/05/6312-0013\$30.00/0 doi:10.1016/i.joms.2005.08.012
}

to the venom have resulted in hemolytic anemia, convulsions, renal failure, shock, disseminated intravascular coagulation, and rarely, death. ${ }^{2}$

Brown recluse spider bites usually occur on the extremities or the trunk, but bites to the face have been reported. ${ }^{3-5}$ Treatment of a brown recluse spider bite is controversial and ranges from conservative comfort measures including rest, ice compresses, and elevation, to drug therapy and surgical excision.

\section{Report of a Case}

In December 2003 an 18-year-old white man stationed at a nearby Army base was referred to our Level I trauma center for evaluation and treatment of a facial cellulitis. He reported that he had been bitten by a brown recluse spider on the chin 2 days prior to admission. He claimed that this was his third attack by a brown recluse, with 2 prior bites to his right leg and torso, respectively. The day following the bite he noticed a "pimple" on his chin in the area of the bite. He experienced increasing erythema, warmth, and tenderness in the area extending to the right of his midline. Treating doctors at the Army base placed the patient on amoxicillin/clavulanate potassium (Augmentin; GlaxoSmithKline, Research Triangle Park, NC) for suspected facial cellulitis secondary to a spider bite. Upon arrival to our hospital, the patient's oral temperature measured $101.2^{\circ}$; blood pressure and heart rate were within normal range. His white blood cell count was elevated to 15,600 . The remaining blood count and complete metabolic profile were within the normal ranges.

The patient presented with erythema and edema of the chin and right face (Fig 1). Induration extended from the left margin of the chin and lower lip to the soft tissues lateral to the body of the mandible on the right. This area was tender to palpation as was the right submandibular area, which was soft. The area of the bite now appeared to have a purplish halo surrounding a whitish center. Intraorally, a small, ulcerated area was present on the lower labial mucosa close to the midline. Fullness and tenderness of the labial and right buccal vestibules were noted. Tenderness of the right sublingual and submandibular spaces was also elicited upon bimanual exam; however, no soft tissue edema was appreciated. His dental exam was unremarkable.

Past medical history was significant only for 2 prior brown recluse spider envenomations. He was taking no medications regularly and reported no known allergies. Prior surgeries included an appendectomy and tonsillectomy. He was an enlisted soldier at a local Army base and denied any tobacco, alcohol, or illicit drug use. 


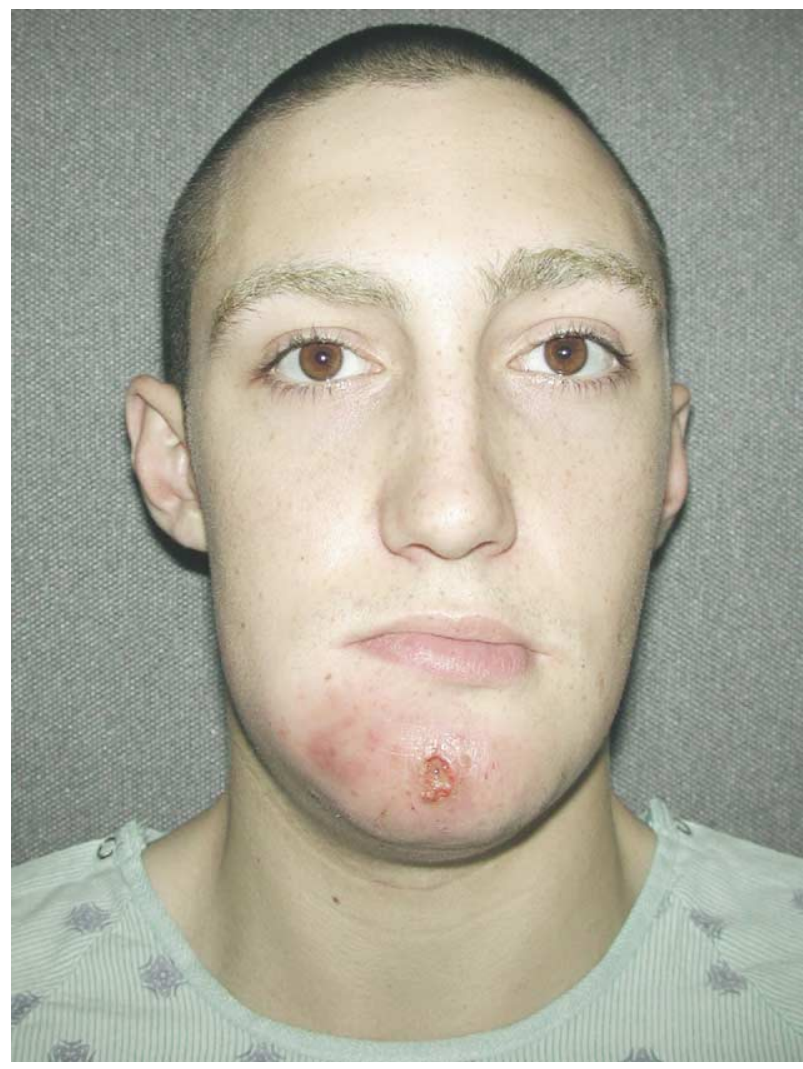

FIGURE 1. The patient presented with erythema and edema of the chin and right face.

Madion et al. Brown Recluse Spider Bite to the Face. J Oral Maxillofac Surg 2005.

The patient was admitted to the hospital for close observation. He was treated conservatively with rest, ice compresses to his face, and elevation of his head. He was placed on intravenous benadryl and clindamycin. Computed tomography scan exhibited right-sided facial soft tissue edema but no other lesions were noted (Fig 2).

Over the next 24 hours the patient's condition worsened. Increasing erythema and edema with induration were noted. The wound clearly exhibited purulent material and the oral communication increased in size. The patient also complained of increasing pain. He was taken to the operating room for incision and drainage of the submental abscess and for extraoral and intraoral debridement of the necrotic tissue (Fig 3). Cultures taken in the operating room returned positive for methicillin-resistant Stapbylococcus aureus and the patient was placed on intravenous vancomycin per sensitivities. Postoperatively, his facial erythema and edema resolved quickly and his wound was allowed to heal by secondary intention with regular, sterile dressing changes (Fig 4). The patient was subsequently transferred back to the Army base for definitive treatment that included scar revision (Fig 5).

\section{Discussion}

The brown recluse spider mainly inhabits the Midwestern United States, from eastern Nebraska to southwestern Ohio. The north-south boundaries run from southern Missouri, Illinois, and Indiana to the Gulf of Mexico excluding Florida. ${ }^{6}$ It prefers dark, well-hidden habitats such as closets or basements. The brown recluse is essentially nonaggressive, and will not bite unless threatened. The spider ranges in size from 1 to $5 \mathrm{~cm}$ in length from leg to leg and is tan to light brown in color. Two distinctive features include a fiddle-shaped brown marking on the spider's dorsal thorax and the presence of 6 eyes arranged in 3 dyads as opposed to the 8 eyes of most spiders (Fig 6). ${ }^{7}$

Diagnosis of a brown recluse spider bite is often difficult. To date, there is no specific serologic, biochemical, or histologic test to effectively diagnose envenomation by the brown recluse spider. Moreover, the potential causes of dermonecrotic lesions are extensive and include bacterial or fungal infection, viruses, drug reactions, pyoderma gangrenosum, other arthropod bites, focal vasculitis, thromboembolic phenomena, Lyme disease, neoplasms, chemical burns, and factitious injections. ${ }^{6,7,9}$ Some of these diseases can be diagnosed with simple tests and if overlooked could have devastating consequences. Therefore, when confronted with a dermonecrotic lesion, the clinician should not rush to diagnose a spider bite without considering all of the potential causes. The literature is abound with evidence that brown recluse spider bites are overdiagnosed, especially in those areas where the spider is not endemic. ${ }^{7,9}$ According to Anderson, ${ }^{1}$ the main criteria for diagnosing envenomation by a brown recluse

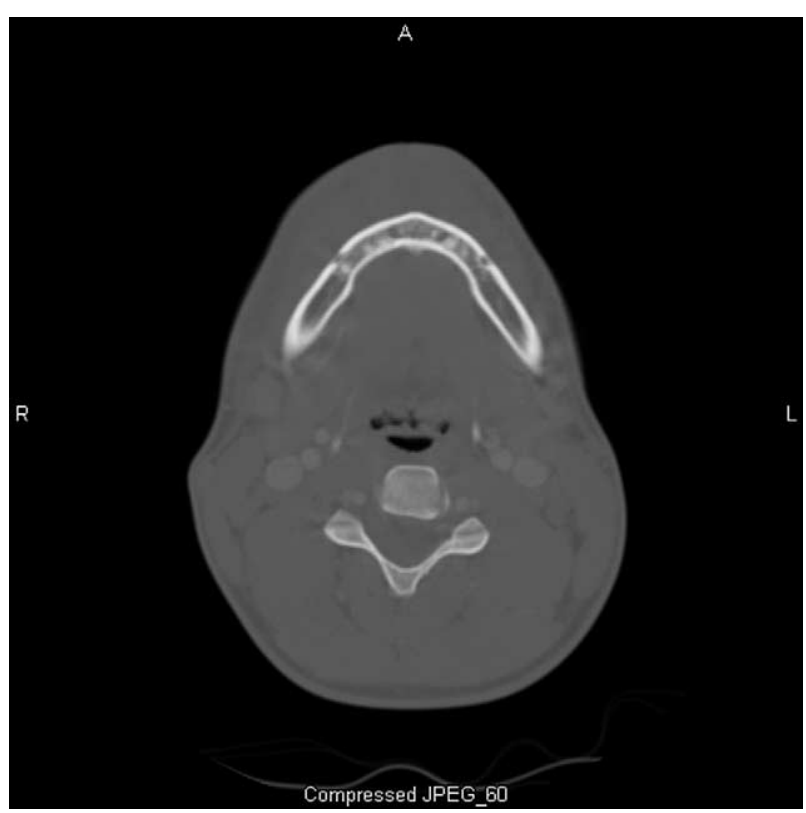

FIGURE 2. Computed tomography scan exhibited right-sided facial soft tissue edema but no other lesions were noted.

Madion et al. Brown Recluse Spider Bite to the Face. J Oral Maxillofac Surg 2005. 

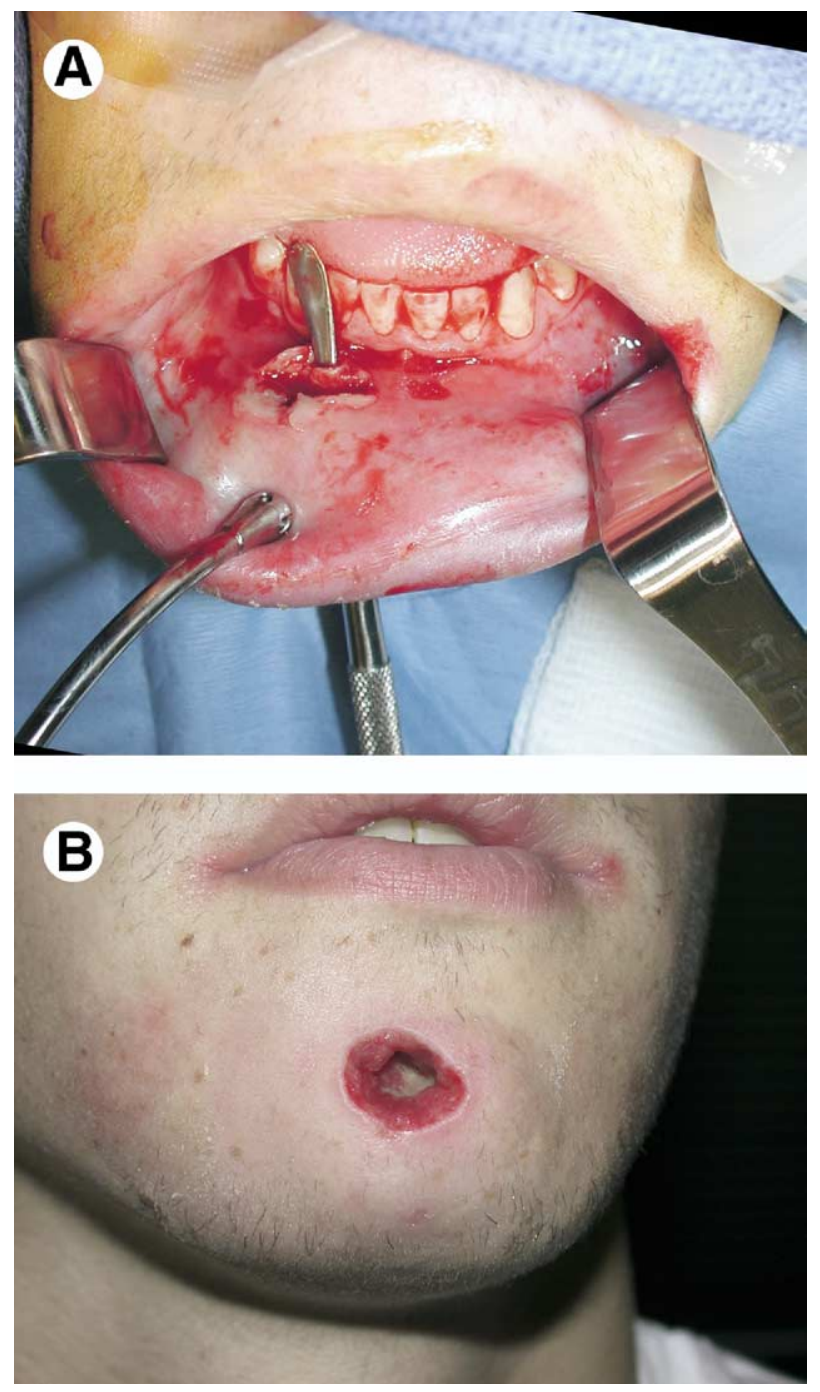

FIGURE 3. $A$, Intraoperative photograph demonstrates through and through nature of wound. B, After debridement of necrotic tissue.

Madion et al. Brown Recluse Spider Bite to the Face. J Oral Maxillofac Surg 2005.

should be that the spider is recovered in the immediate proximity of the bite and its species verified by an experienced entomologist. Gomez et $\mathrm{al}^{10}$ identified a Loxosceles species venom enzyme-linked immunosorbent assay (ELISA) that accurately identified the venom at less than $40 \mathrm{ng} / 100 \mu \mathrm{L}$ homogenized rabbit tissue. At higher concentrations of venom, the assay cross-reacted with 8 of the 17 species tested. Although not yet in clinical use, if applicable in humans this assay may prove to be valuable because it can at least identify the presence of an arthropod venom in the patient. ${ }^{10}$

The venom is the etiologic agent responsible for the cutaneous necrosis. It is a low-molecular-weight, water-soluble protein expected to spread rapidly within the subcutaneous tissues. ${ }^{8}$ Purified venom fractions were found to be cytotoxic to endothelial cells and red blood cells. The venom attracts neutrophils (PMN), which bind to the endothelium, but do not leave the vasculature. Rather, these PMNs degranulate within the vessels causing thrombosis, which leads to ischemia and necrosis of the area. Many claim that the amount of necrosis observed in some patients is too extensive to be caused by the venom alone. This suggests that there may also be an autoimmune component to the tissue injury. Healing is slow in proportion to the size of the infarction, but all lesions should heal eventually. Considering the excellent blood supply to the face, it seems that necrosis would be limited relative to the extremities or areas with a significant amount of adipose tissue. Perhaps, this explains why our patient experienced a relatively short course, 2 to 3 weeks in total, from envenomation to healing by secondary intention. Treatment of cutaneous loxoscelism is controversial and ranges from conservative comfort measures to medical and surgical management. Recommendations for treatment of these injuries are primarily based on anecdotal observations or uncontrolled studies. Controlled treatment studies have been performed on animals, but little empiric evidence exists to support the variety of treatments used in humans. There is general agreement on the ultimate success of comfort measures, including rest, ice compresses to and elevation of the affected area, as well as analgesics/ antipruritics as needed. Systemic antibiotics are also indicated if the lesion becomes secondarily infected, as it did in our case. Realizing that there may be an autoimmune component to the tissue breakdown, studies using systemic corticosteroids as treatment have been performed, but they have shown no appreciable benefit. ${ }^{1}$

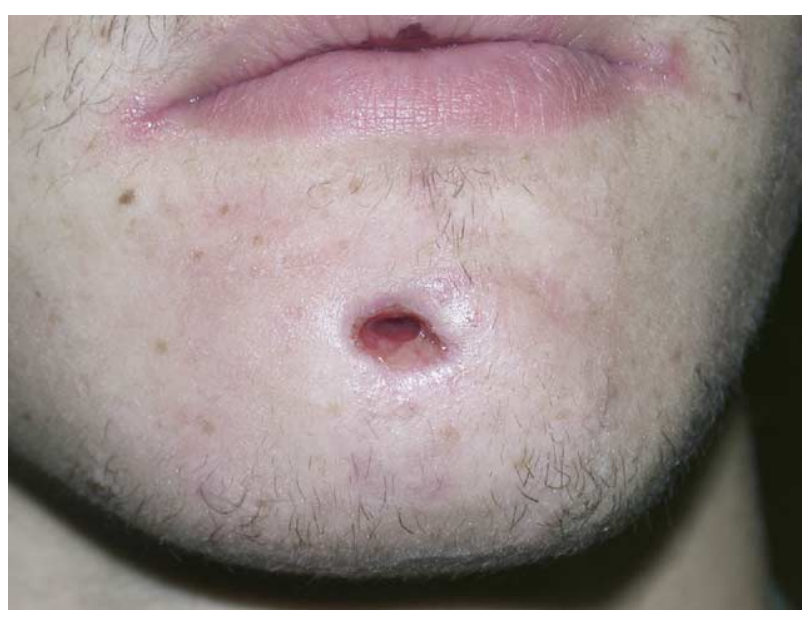

FIGURE 4. Postoperatively, facial erythema and edema resolved quickly and the wound was allowed to heal by secondary intention with regular, sterile dressing changes.

Madion et al. Brown Recluse Spider Bite to the Face. J Oral Maxillofac Surg 2005. 

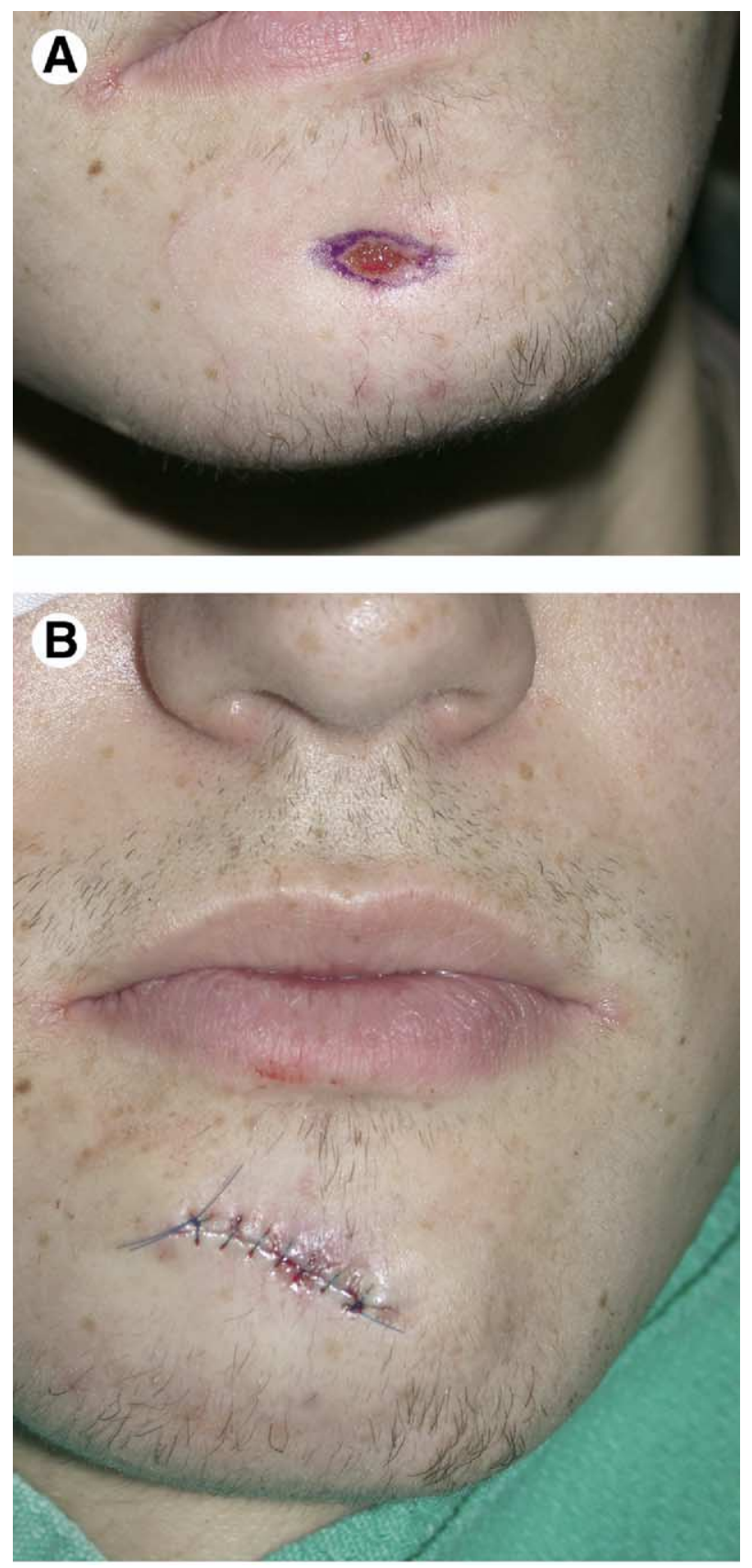

FIGURE 5. Definitive treatment included scar revision. A, Preoperative; $B$, Postoperative.

Madion et al. Brown Recluse Spider Bite to the Face. J Oral Maxillofac Surg 2005.

Dapsone ( $4,4^{\prime}$ diaminodiphenylsulfone), a leukocyte inhibitor used for leprosy, has shown some promise especially if administered early, before necrosis. ${ }^{4,11}$ This treatment has some rationale in that the mechanism of injury is PMN infiltration into the vasculature, which results in thrombosis and subsequent ischemia with necrosis. Dapsone is thought to inhibit this inflammatory aggregate, thus minimizing tissue damage. Dapsone is not without side effects, how- ever, and patients must be screened for glucose-6dehydrogenase deficiency and met-hemoglobinemia because of the potential risks of hemolysis and agranulocytosis. $^{7}$ Other therapies including vasodilators, heparin, hyperbaric oxygen, and electric shock treatment have been tried, but all have failed to show a significant benefit over no treatment.

Surgical intervention, in the form of curettage or complete excision of the lesion, is based on the presumption that removing the venom from the tissue early will minimize necrosis of the area. ${ }^{12}$ Others found that delayed surgical excision, in combination with dapsone, yielded better results than early surgical intervention alone. There was less incidence of delayed wound healing, infection, and objectionable scarring if surgery was delayed until the lesion was more defined and a mature eschar had formed. ${ }^{13}$ Those in favor of conservative management would argue that surgical excision is overtreatment of a condition that will ultimately heal without any type of intervention.

Rees et $\mathrm{al}^{4}{ }^{4}$ developed an antivenom in the rabbit model that exhibited a dose- and time-dependent ability to prevent tissue damage. It was shown to be most effective in those subjects that had not yet developed the clinical lesion. Unfortunately, no such antivenom is available for clinical use in humans.

Our patient's presentation was typical for cutaneous loxoscelism of the face, with a relatively small lesion but a large area of erythema and soft tissue edema. ${ }^{12}$ Fortunately, he had no signs of serious systemic involvement. He was initially

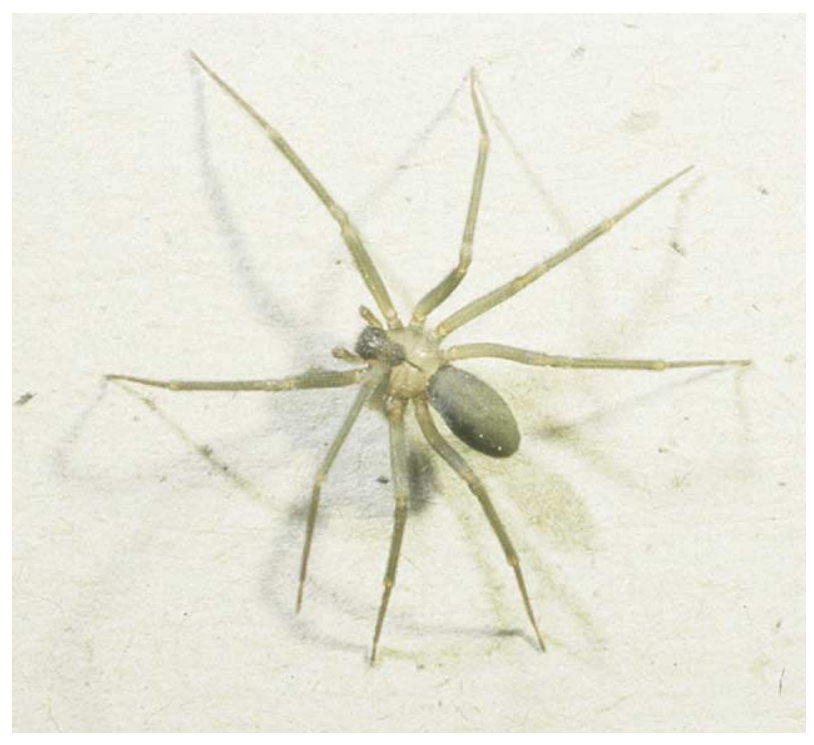

FIGURE 6. Two distinctive features of the brown recluse spider include a fiddle-shaped brown marking on the spider's dorsal thorax and the presence of 6 eyes arranged in 3 dyads.

Madion et al. Brown Recluse Spider Bite to the Face. J Oral Maxillofac Surg 2005. 
treated conservatively, with rest, ice compresses to his face, and elevation of his head. He was then treated surgically with incision and drainage, followed by debridement of the necrotic tissue only after the lesion became secondarily infected. He ultimately responded well to treatment and his wound healed by secondary intention within 3 weeks of the initial insult. Presumably caused by the highly vascular nature of the face, the patient's area of necrosis was limited and the healing time was not prolonged. Although surgical intervention may have accelerated the healing process, our patient would likely have recovered uneventfully without surgery in the absence of secondary abscess formation.

\section{References}

1. Anderson PC: Spider bites in the United States. Dermatol Clin $15: 307,1997$

2. Silcox MM, Miller L: The brown recluse spider: A sometimes fatal bite. J Emerg Nurs 18:101, 1992
3. Jarvis RM, Neufeld MV, Westfall CT: Brown recluse spider bite to the eyelid. Ophthalmology 107:1492, 2000

4. Rees R, Campbell D, Reiger E, et al: The diagnosis and treatment of brown recluse spider bites. Ann Emerg Med 16:945, 1987

5. Sams HH, Hearth SB, Long LL, et al: Nineteen documented cases of Loxosceles reclusa envenomation. J Am Acad Dermatol 44:603, 2001

6. Wendell RP: Brown recluse spiders: A review to help guide physicians in nonendemic areas. South Med J 96:486, 2003

7. Young VL, Pin P: The brown recluse spider bite. Ann Plast Surg 20:447, 1998

8. Rees R, Shack RB, Withers E, et al: Management of the brown recluse spider bite. Plast Reconstr Surg 68:768, 1981

9. Osterhoudt $\mathrm{KC}$, Zaoutis T, Zorc JJ: Lyme disease masquerading as brown recluse spider bite. Ann Emerg Med 39:558, 2002

10. Gomez HF, Krywko DM, Stoecker VW: A new assay detection of Loxosceles species (brown recluse) spider venom. Ann Emerg Med 39:469, 2002

11. Barrett SM, Romine-Jenkins M, Fisher DE: Dapsone or electric shock therapy of brown recluse spider envenomations. Ann Emerg Med 24:21, 1994

12. Hollabaugh RS, Fernandes ET: Management of the brown recluse spider bite. J Pediatr Surg 24:126, 1989

13. Rees RS, Altenbern DP, Lynch JB, et al: Brown recluse spider bites: A comparison of early surgical excision versus dapsone and delayed surgical excision. Ann Surg 202:659, 1985

\title{
Temporomandibular Joint Ankylosis After Condylar Fracture With Penetration of the Condyle in the Medium Cranial Fossa
}

\author{
Paulo Afonso de Oliveira, Jr, DDS, MS, * \\ Luis Fernando Soares Pires, DDS, \\ Gláucia Soriano Oliveira, DDS, $¥$ and \\ Persio Azenba Faber, DDS, MS』
}

The displacement of the mandibular condyle for the medium cranial fossa is a rare event with few cases reported in world literature; that is because evolutionarily the craniofacial anatomy developed mechanisms of cephalic protection that created fragile zones in the condylar and subcondylar areas where the most important fractures happen, resulting from impact in the mandibular symphyseal area.

Up until 1986, there were reported 21 cases in the English-language literature. Musgrove ${ }^{1}$ in 1977

\footnotetext{
"Coordinator, Piracicaba's Oral and Maxillofacial Surgery Residence Program, APCD/Santa Casa de Misericórdia; Master and Specialist in Oral and Maxillofacial Surgery, Piracicaba, Sao Paulo, Brazil.

†Postgraduate Student in Oral and Maxillofacial Surgery, Univer sity of Michigan Hospital, Ann Arbor, MI; and Resident, Piracicaba's Oral and Maxillofacial Surgery, APCD/Santa Casa de Misericórdia Residence Program, Piracicaba, Sao Paulo, Brazil. $\ddagger$ Private Practice, Piracicaba, Sao Paulo, Brazil.
}

\Chairman, Oral and Maxillofacial Surgery Department of Santa Casa de Misericórida; Master in Implantology, Piracicaba, Sao Paulo, Brazil.

Address correspondence and reprint requests to Dr Pires: Rua Dr Vieira Bueno, 133 apt 32, Cambuí, Campinas-S.P.-Brazil CEP 13024-911; e-mail: luisf.pires@gmail.com ๑ 2005 American Association of Oral and Maxillofacial Surgeons 0278-2391/05/6312-0014\$30.00/0 doi:10.1016/i.joms.2005.08.019 